\title{
0 papel do professor/pesquisador na construção do projeto político pedagógico no Ensino Superior
}

\section{The role of the teacher/researcher in the construction of the political pedagogical project in Higher Education}

\author{
Helena Maria dos Santos Felício*
}

\begin{abstract}
Resumo: O texto tem por objetivo refletir o papel do professor/pesquisador na construção coletiva do Projeto Político-Pedagógico, entendido como um instrumento que organiza e consolida o trabalho pedagógico (ensino, pesquisa e extensão) na Instituição de Ensino Superior. Partindo do pressuposto de que o Projeto Político-Pedagógico estabelece os princípios, as diretrizes e as finalidades das ações pedagógicas, procurou-se evidenciar os referenciais e elementos que fundamentam o processo de construção coletiva do projeto em uma instituição de ensino. Para tal construção, o professor/pesquisador é desafiado a romper com algumas barreiras que a tradição do Ensino Superior construiu ao longo de sua história, bem como assumir posicionamentos que farão diferença no cotidiano institucional.
\end{abstract}

Palavras-chave: Projeto Político-pedagógico. Docência no Ensino Superior. Construção coletiva.

\begin{abstract}
This text reflects on the role of the teacher / researcher in the collective construction of Political-Pedagogical Project, understood as an instrument that organizes and consolidates pedagogical work (teaching, research, and outreach projects) at universities. Based on the assumption that the Political-Pedagogical Project establishes the principles, guidelines and purposes of the pedagogical action, the study tried to point out the references and elements that support the collective construction of the project at universities. To this end, the teacher / researcher is challenged to break down certain barriers that university tradition has built up, and to take a stance that will make a difference in the everyday life of the institution.
\end{abstract}

Keywords: Political-pedagogical project. Teaching in higher education. Collective construction.

\section{Introdução}

O Projeto Político-Pedagógico apresenta-se como um tema emergente entre gestores, professores e pesquisadores dos diferentes níveis e modalidades de ensino em virtude da necessária democratização e melhoria na qualidade do ensino.
Considerando o contexto e as especificidades do Ensino Superior, compreender o que vem a ser o Projeto PolíticoPedagógico, sua finalidade e sua relação com o currículo dos diferentes cursos é condição sine qua non para aprofundarmos a

\footnotetext{
* Doutora em Educação: Currículo; Professora Adjunta na Universidade Federal de Alfenas (UNIFAL-MG); e-mail: hsfelicio@gmail.com

* Doctor in Education: Curriculum; Professor at the Federal University of Alfenas (UNIFAL-MG); e-mail: hsfelicio@gmail.com
} 
questão da qualidade do ensino, da pesquisa e da extensão, sobretudo pelo fato de essa modalidade de ensino ser responsável pela produção do conhecimento e pela formação inicial de profissionais para as diferentes áreas.

De um modo geral, os professores que atuam nas universidades públicas ingressam nessas instituições por intermédio de concursos públicos para a docência, nos quais contam pontos a titulação - especialização, mestrado e doutorado, e a experiência de pesquisa entre outras coisas (PIMENTA; ANASTASIOU, 2002). Assim, entendemos que qualquer pessoa com nível superior $\mathrm{e}$ titulação pode tornar-se professor universitário de uma instituição pública, desde que seja aprovado em concurso público.

Muitas vezes esses professores desconhecem as teorias pedagógicas e seus desdobramentos no cotidiano de uma instituição educacional. Contudo, são contratados para trabalhar com uma determinada disciplina e/ ou objeto de conhecimento, seja no exercício da docência, na pesquisa ou na extensão, não tendo condições de perceber o seu papel, enquanto docentes, no desenvolvimento pedagógico da instituição, tampouco a inter-relação de sua disciplina com as demais disciplinas que integram o currículo de um determinado curso.

Esse fato está sendo interpretado como uma das causas mais graves da fragmentação do currículo nos cursos de graduação, bem como da individualização da docência no interior da Instituição de Ensino Superior, cujo trabalho se mostra cada vez mais solitário e menos coletivo, dificultando a visão do todo enquanto curso e/ou Instituição.

Assim, o presente texto tem o objetivo de refletir sobre o papel do professor/ pesquisador na construção coletiva do Projeto-Político Pedagógico no Ensino
Superior, entendido, segundo afirma Massetto (2003), como instrumento que organiza e consolida o trabalho pedagógico (ensino, pesquisa e extensão) na Instituição de Ensino Superior como um todo e em cada unidade acadêmica.

A unidade acadêmica pode ser considerada a célula vital da instituição educacional, uma vez que é nela que tudo acontece. Instalada no interior de Instituição de Ensino Superior, que também deve construir, em uma dimensão macro, o Plano de Desenvolvimento Institucional (PDI), a unidade acadêmica é o lócus da concepção, da construção, da realização e da avaliação do "seu" projeto, uma vez que precisa organizar o trabalho pedagógico com base no contexto situacional, nos acadêmicos e nos professores/pesquisadores que lá desenvolvem seu trabalho.

Para tanto, nesta reflexão queremos, em primeiro lugar, conceituar o Projeto Político-Pedagógico. Em segundo lugar, analisaremos alguns referenciais que fundamentam o Projeto Político-Pedagógico, bem como alguns elementos necessários à sua construção. Finalmente, refletiremos o papel do professor/pesquisador do Ensino Superior nesse processo de construção.

\section{Conceituando o projeto político pedagógico}

Projeto é um "projétil”, algo que se lança para frente. Segundo Ferreira (1975), projeto é um plano, é um empreendimento a ser realizado a partir de um determinado esquema, é uma ação intencional, com sentido claro, descartando toda e qualquer possibilidade de improvisos.

O contexto educacional define o Projeto Político-Pedagógico como um 
documento, construído coletivamente, que reflete as finalidades de uma instituição educacional, que estabelece princípios, diretrizes, propostas de organização, sistematização e avaliação das atividades desenvolvidas por um estabelecimento educacional como um todo.

Entendido como sistematização, nunca definitiva, o Projeto Político-Pedagógico caracteriza-se como um processo que se aperfeiçoa e se concretiza no próprio desenvolvimento do cotidiano educacional, definindo, por assim dizer, claramente, o tipo de ação educativa que se quer realizar. Segundo Vasconcellos (2000, p. 169), é

um instrumento teórico-metodológico para a intervenção e mudança da realidade. É um elemento de organização e integração da atividade prática da instituição neste processo de transformação.

\section{Mas por que Político-Pedagógico?}

É Político, por um lado, porque diz respeito à arte e à ciência de governar. Ele prevê e dá uma direção à gestão da instituição educacional e deve contar com um processo de envolvimento de todos os profissionais, dos diferentes segmentos da instituição de ensino, nas decisões que definem os princípios e as ações desenvolvidas em função dos objetivos propostos e esperados por tal instituição. Por outro lado, é Pedagógico porque, segundo Veiga (2002a), define as ações educativas necessárias ao cumprimento dos propósitos e da intencionalidade de uma determinada instituição de ensino, contextualizadas culturalmente.

Os vocábulos político e pedagógico assumem significados de serem indissociáveis nesse processo de reflexão e discussão do cotidiano da instituição educacional para a busca de alternativas viáveis à efetivação de sua intencionalidade.
Legalmente, a obrigatoriedade da existência do Projeto Político-Pedagógico em uma instituição educacional foi outorgada pela Lei 9394/96, que estabelece as Diretrizes e Bases da Educação Nacional. No seu artigo 12, a lei determina que "os estabelecimentos de ensino, terão a incumbência de elaborar e executar sua proposta pedagógica”. Ou seja, toda instituição educacional, independentemente do seu nível, deve assumir o trabalho de refletir sobre sua intencionalidade educativa e, consequentemente, definir suas ações.

O fato de cada instituição ter que construir, por força legal, o seu Projeto Político-Pedagógico não deve significar somente a elaboração "burocrática” de um documento que ficará arquivado com os dirigentes da instituição. Muito pelo contrário, tal construção deve reforçar a discussão sobre a descentralização, a democratização e a autonomia da gestão educacional assumida pelo setor nas últimas décadas.

Esse fato demonstra a possibilidade do estabelecimento de diferentes relações no interior da instituição educacional, da discussão coletiva sobre a função social dessa instituição, da participação dos diferentes segmentos em sua gestão, enfim, possibilita inovações na busca de uma educação de qualidade.

A instituição educacional deve ser assumida como uma comunidade educativa que mobiliza o conjunto dos atores sociais e dos grupos profissionais em torno de um projeto comum. Para tal, é preciso demarcar os espaços próprios de ação, pois só na classificação desses limites pode-se alicerçar uma colocação efetiva.

Mais adiante, no seu artigo 14, a Lei 9394/96 garante a "participação dos profissionais da educação no projeto pedagógico”, 
o que reflete a importância da coletividade no trabalho pedagógico de uma determinada instituição educacional. Em outras palavras, a qualidade do ensino e o real desempenho da função social de um estabelecimento de ensino são responsabilidades de todos os agentes que constroem seu cotidiano, seja no setor administrativo ou no pedagógico.

A possibilidade de construção coletiva do Projeto Político-Pedagógico é a oportunidade de a instituição educacional

tomar-se nas mãos, e definir por si, coletivamente, participativamente, os seus compromissos [...]. Essa é a forma de realizar de modo mais acabado o seu caráter cultural, democrático e educativo, junto à comunidade. (CASALI, 2004, p. 4).

Assim, para a construção coletiva do Projeto Político-Pedagógico não basta só a sensibilização e o convencimento dos profissionais da instituição de que é necessário construí-lo, mas, segundo Veiga (2002a), é necessário oferecer situações que lhes permitam aprender a pensar e a realizar o fazer pedagógico de forma coerente.

\section{Referenciais que fundamentam a construção do projeto político pedagógico}

Definimos como "referenciais” os aspectos que fundamentam o nosso querer enquanto instituição educacional, bem como as posições tomadas pela instituição em relação à sua identidade, finalidade, visão de mundo, de sociedade, de homem, suas fundamentações filosóficas, sociológicas, epistemológicas e metodológicas.

Destacamos quatro referenciais que são considerados imprescindíveis para a construção do Projeto Político-Pedagógico de uma instituição educacional, especificamente para a Instituição de Ensino Superior.

\section{a) Referência Situacional}

É o desvelamento da realidade em que a instituição educacional está inserida. É a sensibilidade de olhar para o contexto e as pessoas, a fim de captar a realidade socioeconômica, política, educacional e ocupacional, considerando-a no momento da construção do Projeto Político-Pedagógico.

Esse é o ponto de partida, uma vez que qualquer Instituição de Ensino Superior é uma instituição social e, portanto, deve preservar e sustentar uma relação próxima e peculiar com o contexto social mais amplo.

Não se trata apenas do contexto geográfico em que a Instituição de Ensino Superior está instituída. É preciso considerar, também, o contexto construído pelos acadêmicos que, independentemente dos locais de origem, compõem no interior da instituição um contexto peculiar.

\section{b) Referência Doutrinal}

Todo processo educacional baseia-se em uma visão de sociedade e de homem. Assim, a referência doutrinal é a proposta de sociedade, de pessoa, de educação que a Instituição de Ensino Superior assume e reflete nas relações estabelecidas no seu cotidiano, em direção à humanização. Ou seja, a expressão do referencial doutrinal deve ser capaz de "possibilitar que todos os seres humanos tenham condições de ser partícipes e desfrutadores dos avanços da civilização [...] e compromissados com a solução dos problemas que essa mesma civilização gerou." (PIMENTA; ANASTASIOU, 2002, p. 162).

Faz-se necessário explicitar, discutir e assumir coletivamente essa referência para que não haja distorções e nem disparidades 
nas práticas pedagógicas desenvolvidas pelos diferentes profissionais da instituição.

\section{c) Referência Epistemológica}

É a definição de como o conhecimento deve ser considerado e trabalhado pela Instituição de Ensino Superior.

Considerando que uma das principais funções da universidade é a criação, desenvolvimento, transmissão e crítica do conhecimento, o processo de socialização desse conhecimento deve ser definido e assumido, coletivamente, pela instituição.

Garantir a unicidade entre a teoria e a prática nas ações pedagógicas é essencial, visto que o conhecimento produzido pela pesquisa parte do concreto e é fundamentado pela teoria.

Segundo Veiga (2002b, p. 21),

é preciso muita intencionalidade para provocar mudanças no processo de produção do conhecimento. O conhecimento deixa de ser visto numa perspectiva estática e passa a ser enfocado como processo.

A forma como a Instituição de Ensino Superior assume lidar com o conhecimento define os critérios para a organização curricular, para a seleção dos conteúdos e, sobretudo, para o planejamento e desenvolvimentos das aulas por parte dos professores/ pesquisadores.

\section{d) Referência Didático-metodológica}

Esta referência diz respeito às definições de como a sistematização do processo de ensino e de aprendizagem vai ser assumida pela Instituição de Ensino Superior. É importante destacar que tal processo deve ser desenvolvido pelas atividades de ensino, pesquisa e extensão, em uma dimensão integralizadora e inclusiva. Jamais excludente.
Acreditamos que o processo de ensino deve favorecer o processo de uma aprendizagem crítica dos conteúdos por intermédio de metodologias que valorizem a relação ativa dos acadêmicos com o objeto de conhecimento. A mera transmissão de conhecimento em aulas genuinamente expositivas e o treinamento por ações repetitivas não contribuem para o real processo de aprendizagem.

\section{Elementos necessários à construção do projeto político pedagógico}

A construção coletiva do Projeto Político-Pedagógico não se resume a um documento escrito. É um processo amplo que exige comprometimento, esforço coletivo e enfrentamento para a definição dos objetivos e das ações de uma instituição educacional.

É importante mobilizar a comunidade acadêmica para a construção de um processo de educação mais compromissado e democrático, uma vez que sem a vontade coletiva de modificação fica difícil transformar a qualidade da educação.

Segundo Cavagnari (2002, p. 109),

a participação de todos, inclusive dos funcionários, em amplo debate na e sobre a instituição educacional, certamente garantirá o compromisso em executar ações planejadas.

E preciso enfatizar que a construção do Projeto Político-Pedagógico, quando se assume coletivamente, desvela conflitos e contradições. Elimina, porém, as relações competitivas e autoritárias, possibilitando o estabelecimento de relações horizontais no interior da instituição educacional.

Para essa construção é necessário, por um lado, um embasamento teórico-metodológico e, por outro lado, são indispensáveis 
"pesquisas, estudos, reflexões e discussões com professores, especialistas em educação, acadêmicos, determinando o caminho desse processo" (VEIGA, 2002b, p.14).

Dos elementos constitutivos da organização do trabalho pedagógico que devem ser levados em consideração na construção do Projeto Político-Pedagógico, apresentados por Veiga (2002a), destacamos:

\section{a) Finalidade da Instituição:}

A definição da finalidade da Instituição de Ensino Superior deve fundamentar todas as ações desenvolvidas por ela. Insistimos na necessidade de definir não só a finalidade de formação profissional, mas a forma como a instituição prepara os acadêmicos para uma melhor compreensão da sociedade, para a participação política e social, como a instituição promove o desenvolvimento humanístico dos mesmos.

\section{b) Estrutura organizacional:}

Toda Instituição de Ensino Superior dispõe de duas dimensões básicas de estrutura: a administrativa e a pedagógica. Ambas precisam ser assumidas como dimensões integradoras de um mesmo processo.

A estrutura administrativa abrange todos os elementos, de natureza financeira e física, disponíveis para sustentar a estrutura pedagógica, a qual, por sua vez, determina a ação da estrutura administrativa e organiza as funções educativas para que a instituição atinja de forma efetiva as suas finalidades.

\section{c) Currículo:}

O currículo é a forma pela qual organizamos a sistematização do conhecimento, culturalmente selecionado, que deve ser trabalhado no cotidiano da Instituição de Ensino Superior, envolvendo, necessariamente, a interação entre sujeitos que têm um mesmo objetivo e a opção por um referencial teórico que o sustente.

O currículo desvela, sobretudo nas dinâmicas curriculares dos cursos de graduação, a forma como a Instituição de Ensino Superior opta por trabalhar com os processos de ensino e de aprendizagem. Ele expressa uma dimensão formal, que está explícita e decodificada nos documentos da Instituição, bem como uma dimensão oculta, manifestada e transmitida no cotidiano da instituição educacional, sobretudo pelos professores/pesquisadores.

Essas expressões não são neutras. São ancoradas nos pressupostos filosóficos, sociológicos e pedagógicos que fundamentam as crenças e as ações dos profissionais envolvidos tanto na construção do Projeto Político-Pedagógico como em sua implementação.

O ideal seria atingirmos formas de organização curricular em que o conhecimento sistematizado em cada disciplina estabeleça uma relação aberta e integrada com as demais disciplinas e com o todo, com o objetivo de reduzir o isolamento entre as disciplinas curriculares e, consequentemente, entre os professores/pesquisadores.

\section{d) Tempo educacional:}

Na dinâmica curricular dos cursos de graduação, a organização do tempo educacional materializado no calendário e nos horários expressa, de forma mais imediata e em uma visão longitudinal, a maneira como a instituição concretiza sua concepção de currículo.

Quanto mais a organização do tempo educacional se mostrar compartimentalizada, mais ritualizadas e hierarquizadas serão as relações construídas com o conhecimento, 
diminuindo, assim, as possibilidades de se pensar em um currículo integrado.

A sucessão de períodos muito breves dedicados a disciplinas muito diferentes entre si, sem necessidade de sequência lógica entre elas, sem o estabelecimento de relações entre as mesmas, tem o efeito de ensinar aos acadêmicos que o importante não é a qualidade do conhecimento, mas a duração do curso.

\section{e) Processo de decisão:}

A Instituição de Ensino Superior deve prever mecanismos que estimulem a participação comprometida de todos no processo de decisão e promovam a revisão periódica das atribuições específicas e gerais. Para tal, é necessário haver uma distribuição de responsabilidades e um processo de decisão participativo.

Nesse sentido, há necessidade da instalação de mecanismos institucionais de participação de todos os envolvidos com o processo educativo da instituição educacional.

\section{f) Avaliação:}

Acompanhar e avaliar as atividades desenvolvidas pela Instituição de Ensino Superior é a forma de colocar o Projeto Político-Pedagógico em ação. Não estamos falando das "avaliações oficiais", organizadas pelos órgãos competentes. Estamos considerando o processo de avaliação crítica pautada no exercício da reflexão, que busca explicar e compreender as causas das insuficiências e problemas conhecidos, as relações entre essas causas e as necessidades de nelas atuar, buscando ações alternativas criadas coletivamente.

Segundo Saul (2000), esse processo de avaliação do Projeto Político-Pedagógico envolve três momentos: a descrição e problematização da realidade institucional; a compreensão crítica da realidade descrita e problematizada; e a proposição de alternativas de ação, como um momento de criação coletiva.

\section{O papel do professor/pesquisador na construção do projeto político pedagógico da Instituição de Ensino Superior}

Recordando que professor/pesquisador ingressa na Instituição de Ensino Superior, sobretudo nas públicas, mediante a aprovação em concurso para a docência de uma determinada disciplina, é muito comum encontrarmos pesquisadores que se transformam em professores da noite para o dia e acabam por dedicar-se, exclusiva e isoladamente, ao seu objeto de estudo, seja no ensino, na pesquisa ou na extensão.

Esse fato, por vezes, dificulta o desenvolvimento pedagógico da Instituição de Ensino Superior, o qual está expresso em seu Projeto Político-Pedagógico, uma vez que os professores/pesquisadores desenvolvem atividades profundamente significativas, porém de forma isolada.

Assim, o papel do professor/pesquisador, tanto na construção como na implementação do Projeto Político-Pedagógico, configura-se em romper com algumas barreiras que a própria tradição do Ensino Superior construiu ao longo de sua história e assumir alguns posicionamentos que, certamente, farão a diferença no cotidiano institucional.

Oprimeiroposicionamentodizrespeito ao desenvolvimento de uma consciência de pertença à Instituição de Ensino Superior. Como professor/pesquisador, não se pode entender a Instituição do Ensino Superior só como um local de referência para o 
trabalho. Ela é também construída pelo trabalho do professor/pesquisador, que, em contrapartida, incorpora, em seu trabalho, as finalidades, os princípios, os objetivos da Instituição.

O segundo posicionamento relacionase com a necessidade do conhecimento pedagógico que os professores/pesquisadores devem, também, construir: assumir o "ser professor" como uma profissão e, como tal, imbuir-se dos conhecimentos pedagógicos que fundamentam tal profissão. São esses conhecimentos que contribuem para uma melhor compreensão da estrutura e do funcionamento da instituição educacional, nas suas dimensões administrativas e pedagógicas.

O terceiro posicionamento aqui considerado refere-se à participação efetiva dos professores/pesquisadores na construção do Projeto Político-Pedagógico. Tal participação indica a possibilidade de negar toda a tendência de individualização que o trabalho docente, sobretudo no Ensino Superior, tende a expressar. Muito pelo contrário, as ações realizadas pela atividade docente devem refletir-se no Projeto Político-Pedagógico, embora seja respeitada a especificidade de cada profissional.

O quarto posicionamento diz respeito à ação de assumir o Projeto Político-Pedagógico no cotidiano institucional e, consequentemente, comprometer-se com o processo de avaliação constante do mesmo, em função da qualidade dos serviços prestados pela Instituição do Ensino Superior.

\section{Considerações Finais (porém provisórias)}

Entendemos que a construção do Projeto Político-Pedagógico pela Instituição de
Ensino Superior reflete um grande avanço no sistema de ensino. Construir uma Universidade, sobretudo pública, mais comprometida e mais consciente de sua função social significa ter um Projeto Político-Pedagógico real e implementado por todos os agentes educacionais, sobretudo pelos professores/ pesquisadores.

Assim, entendemos que não precisamos de um Projeto Político-Pedagógico "mirabolante". Precisamos de um Projeto realizável e de professores/pesquisadores comprometidos, para além do desenvolvimento profissional e pessoal, com o desenvolvimento institucional. Isto é o que desejamos e esperamos.

\section{Referências}

CASALI, A. M. D. Para a construção de um projeto pedagógico escolar nas escolas integradas, no âmbito do convênio UPMINED. São Paulo: PUCSP, 2004.

CAVAGNARI, L. B. Projeto políticopedagógico, autonomia e realidade escolar: Entraves e contribuições. In: VEIGA, Ilma Passos Alencastro; RESENDE, Lúcia Maria Gonçalves (Orgs.). Escola: espaço do projeto político-pedagógico. 6. ed. Campinas: Papirus, 2002.

FERREIRA, A. B. H. Novo dicionário da língua portuguesa. 5 ed. Rio de Janeiro: Nova Fronteira, 1975.

MASSETTO, M. T. Competência pedagógica do professor universitário. São Paulo: Summus, 2003.

PIMENTA, S. G.; ANASTASIOU, L. G. C. Docência no Ensino Superior. São Paulo: Cortez, 2002. 
SAUL, A. M. Avaliação emancipatória: desafio à teoria e à prática de avaliação e reformulação de currículo. 5. ed. São Paulo: Cortez, 2000.

VASCONCELLOS, C. S. Planejamento: projeto de ensino-aprendizagem e projeto político-pedagógico. São Paulo: Libertad, 2000.

VEIGA, I. P. A. (Org.). Projeto políticopedagógico da escola: uma construção possível. 14.ed. Campinas: Papirus, 2002a.

Perspectivas para reflexão em torno do projeto político-pedagógico. In: VEIGA, I. P. A.; RESENDE, L. M. G. (Orgs.). Escola: espaço do projeto político-pedagógico. 6 . ed. Campinas: Papirus, 2002b.

Enviado em: 19/04/2010

Aceito em: 21/06/2011 